\title{
O FINANCIAMENTO DA EDUCAÇÃO PÚBLICA NO BRASIL NA PRÓXIMA DÉCADA ${ }^{1}$
}

\author{
Gil Vicente Reis de Figueiredo ${ }^{2}$ \\ Universidade Federal de São Carlos (UFSCar)
}

\section{RESUMO}

Está sendo amplamente discutido no Brasil, com a participação da sociedade civil, do Governo e do Congresso, um Plano Nacional de Educação, a vigorar no período 20112020. No Congresso, uma versão preliminar, que propõe um investimento de $10 \%$ do Produto Interno Bruto (PIB) em educação, foi aprovada na Câmara Federal e está agora sendo debatida no Senado. Ao mesmo tempo, uma Conferência Nacional de Educação, a CONAE 2014, irá acontecer em 2014, sendo precedida por Conferências Estaduais e Municipais. Espera-se que dela participem vários milhões de pessoas e é bastante provável que a tese da destinação dos $10 \%$ do PIB para a educação seja aí reforçada. Por outro lado, o investimento em educação foi, em 2011, de 5\% do PIB. Dessa forma, parece relevante discutir, a este ponto, de onde viriam os restantes 5\% do PIB. Propomos aqui que uma alternativa poderia ser alocar para a educação todos os recursos advindos do Fundo Social que será composto a partir dos recursos provenientes da exploração de petróleo, considerando, em especial, os imensos depósitos de óleo fóssil descobertos recentemente na camada do pré-sal.

Palavras-chave: Educação Brasileira. Financiamento. Plano Nacional de Educação.

\section{FINANCING PUBLIC EDUCATION IN BRAZIL: THE NEXT DECADE}

\begin{abstract}
A National Education Plan (2011-2020) is nowadays being widely discussed in Brazil, through a participatory process involving the civil society, the Government and the Congress. In the Congress, a preliminary version, which proposes an investment of $10 \%$ of the Gross Domestic Product (GDP) in education, was approved by the House of Representatives (the Brazilian 'Câmara Federal'), and is now under debate in the Senate. At the same time, a National Conference on Education (CONAE-2014)) will be held in 2014, being preceded by State and Municipal Conferences, in which it is expected that several million people will attend, and it is quite likely that the thesis of investing $10 \%$ of GDP in education will be reinforced there. On the other hand, the investment in education was approximately 5\% of the GDP in 2011 and therefore it seems to be relevant, at this point, to discuss possible sources for the remaining $5 \%$. We propose here that one alternative might be to allocate for educational purposes all the resources coming from a social fund ('Fundo Social') to be composed by petroleum exploration resources, especially if one considers the newly discovered huge deposits of fossil fuel below the Brazilian continental shelf ('pré-sal').
\end{abstract}

Keywords: Brazilian Education. Financing. National Education Plan. 


\section{Introdução}

O Plano Nacional de Educação (PNE) aprovado pela Câmara dos Deputados e atualmente em debate no Senado (PLC 103/2010) prevê que, até 2020, seja destinada à educação brasileira parcela equivalente a $10 \%$ do Produto Interno Bruto (PIB) do Brasil.

Como, no ano de 2011, esse aporte foi de aproximadamente 5\%, é preciso debater de que outras fontes proviriam os restantes $5 \%$.

Uma dessas fontes poderia ter como origem os recursos provenientes da exploração do petróleo, do gás natural de outros hidrocarbonetos fluídos existentes no território nacional, que, com muita probabilidade, passarão a dar receitas substantivas à União nas próximas décadas, em especial como consequência da extração das riquezas da chamada camada do 'pré-sal'.

A distribuição dos recursos financeiros gerados dessa forma tem sido regulamentada através de legislação que fixa as respectivas destinações, com destaque para a Lei № 9.478, de 6 de agosto de $1997^{3}$, para a Lei № 12.351 , de 22 de dezembro de $2010^{4}$ e, recentemente, para a Medida Provisória № 592, de 3 de dezembro de 2012, que modifica as duas leis mencionadas, para determinar novas regras de distribuição, entre os entes da Federação, dos royalties e da participação especial decorrentes da exploração de petróleo, gás natural e outros hidrocarbonetos fluidos sob o regime de concessão; em particular, aí são fixados os montantes a serem destinados ao FS - 'Fundo Social', a serem canalizados para a educação, a cultura, o esporte, a saúde pública, a ciência e tecnologia, o meio ambiente e atividades de adaptação às mudanças climáticas ${ }^{5}$.

\section{Considerações sobre a Lei № 9.478}

\section{- Regime de concessão}

Na Lei № 9.478, ao Conselho Nacional de Política Energética (CNPE), vinculado à Presidência da República e presidido pelo Ministro de Estado de Minas e Energia, foi atribuída a tarefa - dentre outras - de definir os blocos a serem objeto de concessão e a estratégia/política de desenvolvimento econômico e tecnológico da indústria de petróleo e fontes de energia similares. Já a ANP - Agência Nacional do Petróleo - foi incumbida de "promover a regulação, a contratação e a fiscalização das atividades econômicas integrantes da indústria do petróleo, do gás natural e dos biocombustíveis".

Ressalte-se que, pelo regime concessão, de acordo com essa Lei:

[é do] concessionário a obrigação de explorar, por sua conta e risco e, em caso de êxito, produzir petróleo ou gás natural em determinado bloco, conferindo-lhe a propriedade desses bens, após extraídos, com os encargos relativos ao pagamento dos tributos incidentes e das participações legais ou contratuais correspondentes (grifo nosso).

A Lei em questão não trata, pois, do regime de partilha; os trechos da mesma em que essa questão é mencionada foram introduzidos posteriormente pela Lei № 12.351 . 
Quanto às receitas governamentais no regime de concessão, a Lei № 9.478 estabelece os 'royalties' e as "participações especiais", são também previstos o "bônus de assinatura" e o "pagamento pela ocupação ou retenção da área".

\section{- Distribuição de royalties no regime de concessão}

A regulamentação da distribuição dessas riquezas, quer dizer, o valor dos royalties no regime de concessão para contratos firmados até o dia 2 de dezembro de 2012 - antes da MP 592, é estipulado pela Lei № 9.478 em $10 \%$ da produção, podendo a ANP prever a sua redução para $5 \%$ da produção, no mínimo, em função de "riscos geológicos, expectativas de produção e outros fatores pertinentes".

A forma de distribuição desses royalties é determinada nos seus Art.48 e 49.

Pelo Art. 48, a parcela que representar 5\% da produção (o mínimo previsto) é dividida de acordo com os critérios estipulados pelo Art. $7^{\circ}$ da Lei № 7.990, de 28 de dezembro de 1989, que remete ao Art.27 da Lei № 2.004, de 3 de outubro de 1953, ao qual dá a seguinte redação:

I - no caso dos Estados, Distrito Federal e Municípios onde se fixar a lavra do petróleo ou se localizarem instalações marítimas ou terrestres de embarque ou desembarque de óleo bruto ou de gás natural:

a) $70 \%$ aos Estados produtores;

b) $20 \%$ aos Municípios produtores; e

c) $10 \%$ aos Municípios afetados por operações de embarque/desembarque;

II - no caso dos Estados, Distrito Federal e Municípios confrontantes, quando a lavra for extraída da plataforma continental, dos 5\% serão destinados:

a) $30 \%$ aos Estados e Distrito Federal onde se localizarem instalações marítimas ou terrestres de embarque/desembarque;

b) $10 \%$ aos Municípios onde se localizarem instalações marítimas ou terrestres de embarque/desembarque;

c) 30\% aos Municípios produtores e suas áreas geoeconômicas;

d) $20 \%$ ao Ministério da Marinha;

e) $10 \%$ para Fundo Especial a ser distribuído entre todos os Estados, Distrito Federal e Municípios.

Já pelo Art. 49, a parcela do valor do royalty que exceder a 5\% da produção é dividida de acordo com os critérios abaixo:

I - no caso da lavra ocorrer em terra ou em lagos/ilhas fluviais e lacustres:

a) $52,5 \%$ para os Estados produtores;

b) $15 \%$ para os Municípios produtores;

c) 7,5\% aos Municípios afetados por operações de embarque/desembarque; e 
d) $25 \%$ ao Ministério da Ciência e Tecnologia (MCT), para financiar pesquisa aplicada à indústria do petróleo.

II - no caso da lavra ocorrer na plataforma continental:

a) $22,5 \%$ aos Estados produtores confrontantes;

b) $22,5 \%$ aos Municípios produtores confrontantes;

c) $15 \%$ ao Ministério da Marinha (fiscalização/proteção);

d) 7,5\% aos Municípios afetados por operações de embarque/desembarque;

e) 7,5\% para Fundo Especial, a distribuir entre todos os Estados, Territórios e Municípios; e

f) $25 \%$ ao MCT, para financiar pesquisa aplicada à indústria do petróleo.

No que respeita a contratos firmados a partir do dia 3 de dezembro de $2012 \mathrm{em}$ diante, a MP 592 determina nova forma de distribuição dos royalties dos contratos de concessão.

Conforme o Art. 48A, a parcela que representar 5\% da produção (o mínimo previsto) será dividida da seguinte maneira:

I - quando a lavra ocorrer em terra ou em lagos, rios, ilhas fluviais e lacustres, segundo os critérios estipulados pelo Art. 48 desta Lei;

II - quando a lavra ocorrer na plataforma continental, no mar territorial ou na zona econômica exclusiva, na forma do Anexo I a esta Lei.

No primeiro caso fica mantida a forma de distribuição anteriormente prevista pela Lei 9.478, Art. 48; no segundo, é alterada a forma de distribuição anteriormente prevista pela mesma Lei, em especial no que se refere à parte da União, uma vez que o Anexo I em questão prevê que esta passará a receber $20 \%$ dos royalties, enquanto, na formulação anterior, não receberia nada.

O Art. $49^{\mathrm{a}}$ regulamente a maneira pela qual será dividida a parcela que exceder a $5 \%$ da produção:

I - quando a lavra ocorrer em terra ou em lagos, rios, ilhas fluviais e lacustres, segundo a forma estipulada pelo inciso I do caput do art. 49;

II - quando a lavra ocorrer na plataforma continental, no mar territorial ou na zona econômica exclusiva, na forma do Anexo II a esta Lei. (Incluído pela Medida Provisória № 592, de 2012).

Igualmente, no primeiro caso fica mantida a forma de distribuição anteriormente prevista pela Lei 9.478, Art. 48; no que tange ao item II, altera-se a forma de distribuição, notadamente no que respeita à parte da União, já que o Anexo II mencionado se volta para o recebimento de parcela de $20 \%$ dos royalties, sem especificar, como na formulação anterior, destinação específica. 


\section{- Distribuição de participações especiais no regime de concessão}

A existência de 'participações especiais' é prevista no Art. 50 da Lei 9.478, "nos casos de grande volume de produção, ou de grande rentabilidade". Essas "participações especiais' são aplicadas sobre a receita bruta de produção, deduzidos os royalties, os investimentos na exploração, os custos operacionais, a depreciação e os tributos previstos na legislação em vigor.

Para contratos firmados até o dia 2 de dezembro de 2012, a forma de distribuição de 'participações especiais' é determinada também pelo Art. 50, $\S 2^{\circ}$ :

a) $40 \%$ ao Ministério de Minas e Energia;

b) $10 \%$ ao Ministério do Meio Ambiente;

c) $40 \%$ ao Estado onde ocorrer a produção em terra, ou confrontante com a plataforma continental onde se realizar a produção;

d) $10 \%$ ao Município onde ocorrer a produção em terra, ou confrontante com a plataforma continental onde se realizar a produção.

Entretanto, para contratos firmados a partir do dia 3 de dezembro de 2012, a MP 592, ao incluir um $\S 5^{\circ}$ no Art.50 da Lei 9.478, determina outro modo de distribuição de participações especiais dos contratos de concessão:

Art $50[\ldots] \S 5^{\circ}$ Os recursos de participação especial relativos à produção ocorrida nos contratos de concessão firmados a partir de 3 de dezembro de 2012 serão distribuídos na forma do Anexo III a esta Lei.

Tomando-se o Anexo III citado, quanto à parte da União, define-se como sendo inicialmente de $43 \%$, chegando a $46 \%$; são também alterados os demais critérios, que passam a prever a existência de um Fundo Especial com até 30\%, para distribuição entre Estados, Distrito Federal e Municípios.

\section{Considerações sobre a Lei № ${ }^{0} \mathbf{1 2 . 3 5 1}$}

\section{- Regime de partilha: áreas do pré-sal e áreas estratégicas}

A Lei № 12.351 cria o Fundo Social - FS, definido pelo Art. 47 como tendo:

natureza contábil e financeira, vinculado à Presidência da República, com a finalidade de constituir fonte de recursos para o desenvolvimento social e regional, na forma de programas e projetos nas áreas de combate à pobreza e de desenvolvimento: I - da educação; II - da cultura; III - do esporte; IV - da saúde pública; V - da ciência e tecnologia; VI - do meio ambiente; e VII - de mitigação e adaptação às mudanças climáticas.

O Art. 48 determina ainda que os objetivos do FS são: 
I - constituir poupança pública de longo prazo com base nas receitas auferidas pela União; II - oferecer fonte de recursos para $\mathrm{o}$ desenvolvimento social e regional, na forma prevista no art. 47; e III mitigar as flutuações de renda e de preços na economia nacional, decorrentes das variações na renda gerada pelas atividades de produção e exploração de petróleo e de outros recursos não renováveis.

Quanto ao regime de exploração e de produção do petróleo, do gás natural e de outros hidrocarbonetos fluidos na área do pré-sal e em áreas estratégicas, a Lei № 12.351 estipula, em seu Art. $3^{\circ}$, que será o de partilha de produção; este é definido, no Art. $2^{\circ}$, como sendo aquele no qual:

o contratado exerce, por sua conta e risco, as atividades de exploração, avaliação, desenvolvimento e produção e, em caso de descoberta comercial, adquire o direito à apropriação do custo em óleo, do volume da produção correspondente aos royalties devidos, bem como de parcela do excedente em óleo, na proporção, condições e prazos estabelecidos em contrato.

O texto da Lei, com o objetivo de dar precisão ao conceito de partilha, esclarece ainda que, o ‘custo em óleo' é a:

parcela da produção [...] exigível unicamente em caso de descoberta comercial, correspondente aos custos e aos investimentos realizados pelo contratado na execução das atividades de exploração, avaliação, desenvolvimento, produção e desativação das instalações, sujeita a limites, prazos e condições estabelecidos em contrato.

E que o 'excedente em óleo', refere-se à:

parcela da produção [...] a ser repartida entre a União e o contratado, segundo critérios definidos em contrato, resultante da diferença entre o volume total da produção e as parcelas relativas ao custo em óleo, aos royalties devidos e, quando exigível, à participação de que trata o Art. $43^{6}$.

No que tange às receitas governamentais no regime de partilha de produção, a Lei № 12.351 define que serão os royalties, no valor de $15 \%$ da produção, e, sobretudo, parcela do 'excedente em óleo' (sendo que há, ainda, os bônus de assinatura).

\section{- Distribuição de royalties no regime de partilha}

A Lei № 12.531 estabelece (Art. 42-B) que os royalties devidos em função da produção de petróleo, de gás natural e de outros hidrocarbonetos fluidos sob o regime de partilha de produção serão distribuídos conforme a seguir se apresenta, destacando-se que o inciso II do referido artigo, item f, já traz a alteração introduzida pela MP № 592:

I - quando a produção ocorrer em terra, rios, lagos, ilhas lacustres ou fluviais:

a) $20 \%$ para os Estados ou o Distrito Federal, se for o caso, produtores; 
b) $10 \%$ para os Municípios produtores;

c) $5 \%$ para os Municípios afetados por operações de embarque e desembarque de petróleo, gás natural e outro hidrocarboneto fluido, na forma e critérios estabelecidos pela ANP;

d) $25 \%$ para constituição de fundo especial, a ser distribuído entre Estados e o Distrito Federal, se for o caso, de acordo com o seguinte critério: o rateio dos recursos do fundo especial obedecerá às mesmas regras do rateio do Fundo de Participação dos Estados e do Distrito Federal (FPE), de que trata o Art. 159 da Constituição Federal (CF);

e) $25 \%$ para constituição de fundo especial, a ser distribuído entre os Municípios de acordo com o seguinte critério: o rateio dos recursos do fundo especial obedecerá às mesmas regras do rateio do Fundo de Participação dos Municípios (FPM), de que trata o Art. 159 da CF;

f) $15 \%$ para a União, a ser destinado ao FS, instituído por esta Lei, deduzidas as parcelas destinadas aos órgãos específicos da Administração Direta da União, nos termos do regulamento do Poder Executivo;

II - quando a produção ocorrer na plataforma continental, no mar territorial ou na zona econômica exclusiva:

a) $22 \%$ para os Estados confrontantes;

b) $5 \%$ para os Municípios confrontantes;

c) $2 \%$ para os Municípios afetados por operações de embarque e desembarque de petróleo, gás natural e outro hidrocarboneto fluido, na forma e critérios estabelecidos pela ANP;

d) $24,5 \%$ para constituição de fundo especial, a ser distribuído entre Estados e o Distrito Federal, se for o caso, de acordo com o seguinte critério: o rateio dos recursos do fundo especial obedecerá às mesmas regras do rateio do FPE, de que trata o Art. 159 da CF;

e) $24,5 \%$ (vinte e quatro inteiros e cinco décimos por cento) para constituição de fundo especial, a ser distribuído entre os Municípios de acordo com o seguinte critério: o rateio dos recursos do fundo especial obedecerá às mesmas regras do rateio do FPM, de que trata o Art. 159 da CF;

f) $22 \%$ para a União, a ser destinado ao Fundo Social (grifo nosso).

Nesse caso, a MP 592 retirou o restante do texto do item f), anteriormente constante da Lei № 12.351, a saber: "instituído por esta Lei, deduzidas as parcelas destinadas aos órgãos específicos da Administração Direta da União, nos termos do regulamento do Poder Executivo".

\section{- Definição dos recursos que constituirão o Fundo Social}

Os recursos que constituirão o FS são descritos no Art. 49 da Lei № 12.351: 
I - parcela do valor do bônus de assinatura destinada ao FS pelos contratos de partilha de produção [não definida na legislação vigente];

II - parcela dos royalties que cabem à União, deduzidas aquelas destinadas aos seus órgãos específicos, conforme estabelecido nos contratos de partilha de produção, na forma do regulamento [22\% dos royalties de contratos de partilha, quando a produção ocorrer na plataforma continental, no mar territorial ou na zona econômica exclusiva, conforme Art. 42-B];

III - receita advinda da comercialização de petróleo, de gás natural e de outros hidrocarbonetos fluidos da União, conforme definido em lei ${ }^{7}$;

IV - os royalties e a participação especial das áreas localizadas no pré-sal contratados sob o regime de concessão destinado à administração direta da União;

V - os resultados de aplicações financeiras sobre suas disponibilidades;

VI - outros recursos destinados ao FS por lei.

O inciso IV acima trata do que estabelecem os Artigos 48, 48-A, 49, 49-A, 50 e 50A da Lei № 9.478 em relação a contratos em áreas do pré-sal sob o regime de concessão, considerada a MP 592, o que significa: $25 \%$ dos royalties de contratos de concessão firmados até 2 de dezembro de 2012, naquilo que exceder 5\% (Art.48/49); 20\% dos royalties de todos os contratos de concessão firmados de 3 de dezembro de 2012 em diante (Art.48-A e 49-A); 50\% das participações especiais, até 2 de dezembro de 2012 (Art.50, § $2^{\circ}$ ), e entre $43 \%$ e $46 \%$ das participações especiais (Art.50, $\S 5^{\circ}$ ), a partir de 3 de dezembro de 2012 - nossos grifos se referem a recursos a serem destinados exclusivamente para a educação.

Além disso, a MP 592 estabeleceu o seguinte acréscimo importante ao Art. 47 da Lei № 12.531:

$\S 3^{\circ}$ Do total do resultado a que se refere o caput do art. 51 auferido pelo FS, cinquenta por cento deve ser aplicado obrigatoriamente em programas e projetos direcionados ao desenvolvimento da educação, na forma do regulamento.

Registre-se que, conquanto o Art. 47 e o Art. 51 deixem claro que os $50 \%$ obrigatórios para aplicação na educação provenham da "aplicação dos recursos do $F S$ ", o parágrafo único deste último artigo diz que:

Constituído o FS e garantida a sua sustentabilidade econômica e financeira, o Poder Executivo, na forma da lei, poderá propor o uso de percentual de recursos do principal para a aplicação nas finalidades previstas no art. 47, na etapa inicial de formação de poupança do fundo.

Dado o que regulamentam as Leis № 9.478 a № 12.351, assim como a Medida Provisória № 592, é fundamental, de início, fazer uma avaliação da ordem de grandeza dos recursos que estarão sendo aportados ao FS no ano de 2020, ainda que com a óbvia margem de incerteza decorrente de flutuações das variáveis essenciais durante esse largo 
período; do contrário, dificilmente será possível traçar uma política de financiamento para a educação na próxima década.

Não há, portanto, nenhuma pretensão de precisão absoluta nos números que serão apresentados a seguir, a partir da suposição de que o preço do barril de petróleo, medido como percentual do PIB brasileiro, se mantenha relativamente constante nos próximos anos.

É claro que intervirão na correção (ou não) dessa estimativa um conjunto de fatores, dentre outros: a trajetória do preço do barril do petróleo (em dólares); a evolução do câmbio dólar x real; e o crescimento anual do PIB.

Adotaremos, para fins de cálculo, os seguintes parâmetros: preço do barril em US\$ $110^{8}$; câmbio de 1 US\$ $=\mathrm{R} \$ 2,04^{9}$; e PIB de R $\$ 4,4$ trilhões (previsão para 2012). Além disso, suporemos que a produção adicional dos campos do pré-real, em 2020, estará próxima das previsões oficiais ${ }^{10}$ e será, assim, algo em torno de 4 milhões de barris de petróleo ${ }^{11}$ diários em regime de partilha e outros 2,1 milhões em regime de concessão.

\section{Contratos de Partilha: Recursos para o FS em 2020}

Tomando-se os pressupostos acima explicitados, a produção anual de barris de petróleo, em 2020, pelo regime de partilha, seria próxima de 7,45\% do PIB brasileiro ${ }^{12}$.

A Lei № 12.351, contudo, não define de forma precisa qual é a parte do chamado 'excedente em óleo' que caberá ao Estado brasileiro, ou seja, qual é o percentual que lhe é devido do valor que representar o lucro líquido da exploração do pré-sal. De fato, segundo o Art.10 dessa mesma lei, caberá ao Ministério de Minas e Energia (MME) propor ao Conselho Nacional de Política Energética (CNPE) um percentual mínimo, cabendo ao processo licitatório (Art.18) 'identificar a proposta mais vantajosa' ${ }^{13}$.

Na verdade, o estabelecimento de critérios para cálculo do 'excedente em óleo' não é tarefa simples, e, de uma forma geral, a tendência mundial majoritária é a adoção de percentuais progressivos e flexíveis, de modo a garantir a eficiência, a viabilidade e a estabilidade do regime de partilha ${ }^{14}$. Essa flexibilidade se refere à capacidade de adequação a um conjunto de situações pouco previsíveis e eventualmente voláteis, como a instabilidade dos preços do petróleo, a oscilação do câmbio ou as variações nos custos de produção. Em outras palavras, o regime é flexível quando o aumento/declínio da lucratividade gera um aumento/declínio da parcela governamental, respectivamente.

O usual é adotar-se 'escalas móveis' ('sliding scales' na literatura em inglês), que levem em conta uma ou diversas dentre as seguintes variáveis: volume de produção; fator "R" (razão entre a receita acumulada e a despesa acumulada); taxa de retorno ou preço do barril.

Partindo-se dessas considerações, é de se esperar que o percentual do 'excedente em óleo' de propriedade da União venha a se elevar paulatinamente ao longo dos próximos anos. Uma estimativa plausível, dada a experiência mundial (como a de Angola, por exemplo), é que esse percentual alcance, já em 2020, algo em torno dos $60 \%$ do 'excedente 
em óleo', o que poderia significar 40\% do valor total da produção; isso equivaleria a cerca de $3 \%$ do PIB ${ }^{15}$. Esse montante, pela Lei № 12.351, Art.49, inciso III, iria para o FS.

Já os royalties dos contratos em regime de partilha, fixados em 15\%, corresponderiam, em 2020, a um valor aproximado de $1,12 \%$ do PIB $^{16}$, dos quais, de acordo com a MP № 592, Art. $1^{\circ}$, uma parcela de $22 \%$ relativa à parte da União - a saber, $0,25 \%$ do PIB - iria também para o FS.

Dessa maneira, uma estimativa do aporte orçamentário para o FS em 2020 conforme proveniente dos novos contratos de partilha - seria de 3,25\% do PIB.

\section{Contratos de Concessão: Recursos para o FS em 2020}

Os royalties e participações especiais de contratos de concessão já firmados que irão para o FS referem-se aos provenientes da exploração do pré-sal (Lei № 12.351, Art.49, inciso IV) e, em conformidade com as perspectivas aqui apresentados, serão aproximadamente de $0,08 \%$ do $\mathrm{PIB}^{17}$, em 2020. O Art.48, o Art.49 e o Art.50, § $2^{\circ}$, da Lei № 9.478 preveem que seja destinado em torno de um terço desse montante à União, quer dizer, um pouco menos de $0,03 \%$ do PIB. Esses recursos também irão para o FS - a vigorar a MP № 592 (de acordo com seu Art. $2^{\circ}$, que reformula o Art.50-A da Lei № 9.478).

Em resumo, confirmadas as estimativas acima apresentadas, os repasses ao FS em 2020 serão da ordem de $3,3 \%$ do PIB.

\section{Destinação Exclusiva à Educação}

A MP 592 (Art. $2^{\circ}$ ) determina que as receitas de que tratam os artigos 48-A, 49-A e $50, \S 5^{\circ}$, da Lei 9.478 sejam exclusivamente destinadas à educação. Esses valores dizem respeito a royalties e participações especiais relativos a contratos de concessão assinados a partir de 3 de dezembro de 2012 e, por conseguinte, não se referirão a áreas do pré-sal, em respeito à Lei 12.531. Supondo-se que todas as atuais áreas fora do pré-sal (1,8 milhões de barris/dia) venham a ser leiloadas novamente à iniciativa privada sob o regime de concessão, teríamos um volume de royalties e participações especiais da ordem de $0,6 \%$ do $\mathrm{PIB}^{18}$. Em 2020, dos royalties ${ }^{19}, 20 \%$ irão para a União; e das participações especiais ${ }^{20}$, $46 \%$. Ou seja, na melhor das hipóteses a destinação de recursos para a educação, por essa via, alcançará em 2020 o patamar de $0,2 \%$ do PIB.

Além desses 0,2\% do PIB, a MP 592 prevê, em seu Art.1', que "Do total a que se refere o caput do Art.51 (da Lei 12.351) auferido pelo FS, cinquenta por cento deve ser aplicado obrigatoriamente em programas e projetos direcionados ao desenvolvimento da educação, na forma do regulamento". Qual a ordem de grandeza dessa destinação? Para responder a essa pergunta, vale lembrar inicialmente que o 'caput' do Art.51 da Lei 12.351 diz que "Os recursos do FS para aplicação [..] deverão ser os resultantes do retorno sobre o capital". Mais ainda, o Art.50 da mesma Lei postula, em seu Parágrafo Único, que a política de investimentos e aplicações do FS deverá ser direcionada "a ativos no exterior, com a finalidade de mitigar a volatilidade de renda e de preços na economia nacional”. E 
qual é o rendimento que se deve esperar desse tipo de aplicação? Possíveis 'ativos' a considerar seriam os Títulos do Tesouro dos EUA; em meados de 2012, seu rendimento estava em um mínimo histórico: menos de $2 \%$ em 10 anos $^{21}$.

Para avaliar a possível destinação de recursos para a educação, basta ver que, se os recursos destinados ao FS fossem capitalizados entre 2013 e 2020, ao final desse último ano aí estariam, no máximo, perto de $16 \%$ do PIB. Um rendimento de $2 \%$ em 10 anos, calculado sobre esse capital, daria retorno anual de $0,03 \%$ do PIB; e, de acordo com a MP 592, metade disso, ou $0,015 \%$ do PIB, iria para a educação.

Evidencia-se, portanto, que pela legislação - vigente e proposta - a quantidade de recursos do pré-sal prevista para destinação à educação em 2020 equivalerá no máximo a $0,22 \%$ do PIB, sendo assim, irrisória frente ao adicional necessário de 5\%, conforme previsto pelo PNE.

\section{Proposta para a Próxima Década: Todos os Recursos do FS para a Educação}

A análise acima mostra, de maneira clara, que nem a Lei 12.351 nem a MP 592 garantem, ainda que longinquamente, aporte de recursos suficientes para que se alcance no nosso País, no médio prazo, uma educação universal e de qualidade para todos.

Por outro lado, o IBGE prevê que, em poucas décadas, a quantidade de crianças e jovens irá declinar de forma progressiva e acentuada: os brasileiros de 3 anos ou menos, que hoje são mais de 13 milhões, somarão, em 2050, menos de 7 milhões ${ }^{22}$.

Ainda segundo o IBGE, haverá uma rápida inversão da pirâmide etária ao longo desse período, de forma que, adiante, os desafios mais agudos se deslocarão para a área da saúde e previdenciária, dentre outras. Logo, a hora inadiável de investir decididamente em educação é agora. Com isso, estaremos garantindo, em algum tempo mais, o acesso - pleno e com qualidade - da maioria da população a todos os níveis escolares.

A partir de 2020 abrir-se-á espaço para a capitalização crescente do FS, o que seguramente será necessário para enfrentar as múltiplas problemáticas decorrentes da elevação significativa da idade média dos brasileiros, futuramente.

No atual momento, pois, a única proposta razoável é que o Poder Executivo lance mão do parágrafo único do Art. 51 da Lei 12.351, que abre espaço para o "uso de percentual de recursos do principal para a aplicação nas finalidades previstas no art. 47, na etapa inicial de formação de poupança do fundo". Esse percentual terá que alcançar quase a integralidade do FS, nos anos vindouros, com a aplicação de um valor próximo da totalidade dos depósitos dessa poupança em educação - resguardados naturalmente os (pequenos) quantitativos a serem reservados para os Ministérios da Ciência e Tecnologia, Minas e Energia, Meio Ambiente e Marinha, conforme previsto na legislação atual.

Chegaríamos assim a 2020, mantida a destinação exclusiva prevista na MP 592, com algo próximo a $8,5 \%$ do PIB para a educação; mesmo nesse caso, ainda teriam que ser encontradas fontes suplementares; reconheça-se, contudo, que parte importante dos aportes adicionais necessários estaria equacionada. 
A utilização do FS com a finalidade que aqui propomos trará frutos da máxima relevância, não só para o desenvolvimento cultural, científico, tecnológico e econômico do País, mas, sobretudo, para a elevação do grau de equidade social, essencial a um Brasil mais justo e cidadão.

\title{
Fontes:
}

BRASIL - LEI № 9.478, de 6 de agosto de 1997.

BRASIL - LEI № 12.351, de 22 de dezembro de 2010.

BRASIL - MEDIDA PROVISÓRIA № 592, de 3 de dezembro de 2012.

\begin{abstract}
${ }^{1}$ Parte deste texto foi apresentada ao Congresso Nacional em março de 2013 pela Campanha Nacional pelo Direito à Educação, com a devida referência à autoria do mesmo. O deputado André Figueiredo (PDT-CE), relator do Projeto de Lei 323/07, que "Dispõe sobre a destinação para as áreas de educação e saúde de parcela da participação no resultado ou da compensação financeira pela exploração de petróleo e gás natural [...]", acolheu, no substitutivo que apresentou à Câmara Federal, a lógica aqui proposta, no que diz respeito a destinar à educação parte do principal do Fundo Social, e não apenas dos rendimentos deste. Esse substitutivo foi aprovado na Câmara Federal em 25 de junho de 2013, seguindo então para o Senado. http://www.camara.gov.br/proposicoesWeb/prop_mostrarintegra?codteor=1103543\&filename=Tramitacao-
\end{abstract} PL+323/2007. O Senado, por sua vez, aprovou em 04 de julho de 2013 substitutivo ao texto da Câmara Federal, retornando à orientação da proposição original, endossada pelo Governo, que pressupõe destinar à educação apenas parcela dos rendimentos (e não do principal) dos recursos depositados no Fundo Social. http://www.camara.gov.br/proposicoesWeb/prop_mostrarintegra?codteor=1107068\&filename=TramitacaoPL+323/2007. O PL 323/07 retorna à Câmara Federal na segunda semana de julho de 2013.

${ }^{2}$ Professor Associado 4 da UFSCar e PhD pela University of Warwick, Inglaterra. Membro Titular do Fórum Nacional de Educação. Email: gvrf2011@gmail.com

${ }^{3}$ Dispõe sobre a política energética nacional, as atividades relativas ao monopólio do petróleo, institui o Conselho Nacional de Política Energética e a Agência Nacional do Petróleo e dá outras providências. http://www.planalto.gov.br/ccivil_03/leis/19478.htm

${ }^{4}$ Dispõe sobre a exploração e a produção de petróleo, de gás natural e de outros hidrocarbonetos fluidos, sob o regime de partilha de produção, em áreas do pré-sal e em áreas estratégicas; cria o Fundo Social - FS e dispõe sobre sua estrutura e fontes de recursos; altera dispositivos da Lei № 9.478, de 6 de agosto de 1997; e dá outras providências. http://www.planalto.gov.br/ccivil_03/_Ato2007-2010/2010/Lei/L12351.htm

5 Medida Provisória № 592, de 3 de dezembro de 2012. http://www.planalto.gov.br/ccivil_03/_Ato20112014/2012/Mpv/592.htm

${ }^{6}$ O Art. 43 se refere à situação de exploração de bloco em terra, sendo a parcela de até $1 \%$ devida aos proprietários da terra em que se localiza o bloco.

${ }^{7}$ Este item refere-se à comercialização do 'excedente em óleo' da União, isto é, todo o petróleo, gás natural e outros hidrocarbonetos fluídos de propriedade da União no regime de partilha, cujo percentual mínimo cabe ao Ministério de Minas e Energia propor.

8 Consultar: http://www.brasil.gov.br/noticias/arquivos/2011/06/06/producao-de-petroleo-no-brasil-deveatingir-6-1-milhoes-de-barris-em-2020. Acesso em 30 dez 2012. 
${ }^{9}$ Em 28 de dezembro de 2012.

10 Consultar http://www.brasil.gov.br/noticias/arquivos/2011/06/06/producao-de-petroleo-no-brasil-deveatingir-6-1-milhoes-de-barris-em-2020. Acesso em 30 dez 2012.

${ }^{11}$ Levaremos em consideração neste trabalho apenas a produção de petróleo (e não a de outros hidrocarbonetos, gás natural, etc.).

${ }^{12}$ Uma produção de 4 bilhões de barris diários corresponde a 1,46 bilhões barris/ano. Ao preço de mercado de US\$ 110 dólares o barril, o valor desse óleo daria US\$ 161 bilhões ou R\$ 328 bilhões, ou seja, aproximadamente $7,45 \%$ do PIB.

13 Consultar "O novo marco regulatório para a exploração do pré-sal", em: http://www.maxwell.lambda.ele.puc-rio.br/19982/19982.PDF. Acesso em 30 dez 2012.

${ }^{14}$ Consultar "Sucesso do pré-sal depende de regime fiscal adotado", em: http://www.conjur.com.br/2011-abr06/sucesso-pre-sal-depende-regime-fiscal-contratos-partilha\#autores. Acesso em 30 dez 2012.

${ }^{15} 40 \%$ de $7,45 \%$ do PIB.

${ }^{16}$ Ou seja, $15 \%$ de $7,45 \%$ do PIB.

${ }^{17}$ São produzidos hoje cerca de 200 mil barris diários na área do pré-sal, com valor anualizado um pouco superior a $\mathrm{R} \$ 16 \mathrm{bi}$, a saber, $0,37 \%$ do PIB. Desse total, perto de uma quinta parte vai para royalties e participações especiais, isto é, $0,08 \%$ do PIB.

${ }^{18} \mathrm{O}$ volume de royalties e participações especiais seria da ordem de um sexto do valor de mercado de uma produção de 1,8 milhões barris/dia - quase $0,6 \%$ do PIB.

${ }^{19}$ O percentual de $20 \%$ é o determinado pelos Art.48-A e 49-A da Lei № 9.478, conforme os Anexo I e II nela inseridos pela MP 592.

${ }^{20}$ O percentual de $46 \%$ é o determinado (para 2020), pelo Art.50, §5o, conforme o Anexo III nela inserido pela MP 592.

${ }^{21}$ Consultar http://www.infomoney.com.br/mercados/noticia/2451257/rendimento-titulos-tesouro-dos-euarecua-para-minima-historica.

${ }^{22}$ IBGE, 2008, Diretoria de Pesquisas - DPE, Coordenação de População e Indicadores Sociais - COPIS. Projeção da População do Brasil por sexo e idade para o período 1980-2050 - Revisão 2008. Metodologia e Resultados. Brasília, 2008.

Recebido: Fevereiro-2013

Aprovado: Março-2013 